\title{
Pricing vaccines and drugs in Europe: worth differentiating?
}

\author{
Livio Garattini ${ }^{1} \cdot$ Anna Padula $^{1} \cdot$ Nicholas Freemantle $^{2}$
}

Published online: 23 June 2020

(c) Springer-Verlag GmbH Germany, part of Springer Nature 2020

\section{Introduction}

The COVID-19 pandemic has recently brought to the forefront the vital importance of vaccines, of which Europe is the world leader in both development and manufacturing [1]. Although vaccines are considered pharmaceuticals from a regulatory viewpoint, there are substantial differences between vaccines and other pharmaceutical products in terms of both health and economics.

Here we compare drugs and vaccines using a sort of ' $6 \mathrm{P}$ scheme', adding Patient and Patent to the well-known 4P (Product, Place, Promotion, Price) business tool [2] for casting light on the major differences between the two types of products. The final aim is to put forward an original proposal for pricing vaccines in European countries.

\section{Comparative analysis}

\section{Patient}

Drugs are usually administered to patients, i.e., ill/injured subjects in need of treatment regardless of the severity of their health problems. Many drugs can coexist in the same therapeutic class because each of them may have different effects on specific sub-groups of patients.

In contrast, the same vaccines are administered to otherwise healthy individuals, to prevent the same diseases. Wherever high coverage rates are achieved, unvaccinated subjects may benefit too, by reducing the risk of transmission and circulation of pathogens due to the so called 'herd immunity' [3]. Therefore, the social benefits of vaccines can

Livio Garattini

livio.garattini@marionegri.it

1 Centre for Health Economics, Institute for Pharmacological Research Mario Negri IRCCS, Ranica, Italy

2 Institute of Clinical Trials and Methodology, University College London, London, UK exceed the private ones [4]. Conversely, because vaccines can cause a (small) risk of serious adverse effects in healthy individuals-often infants and children-not suffering the targeted diseases, they may be more open to criticism than drugs [4]. This can favor campaigning against them by the so-called 'anti-vax' movements, especially in highly developed countries which have not experienced pandemics for decades before COVID-19.

\section{Patent}

Patents are crucial for maximizing financial returns on drugs' research investments, even after the first invention, which is part of a harsh debate in the pharmaceutical literature [5]. To limit the turnover of off-patent medicines, pharmaceutical companies often recur to secondary patenting for dramatically prolonging protection (the so called 'ever greening' strategies). Secondary patents on drugs are usually applied to new indications and 'me-too' drugs. Besides patents on products, complex biological drugs, such as the recent monoclonal antibodies (mABs) can be further protected on production phases that affect their final mechanism [6].

Differently, patents are less relevant for vaccines, mainly protecting manufacturing processes rather than antigens [7]. In fact, patents on products cannot prevent other companies from using different strains to supply competing vaccines [4]. Because vaccines are all biological agents to date-awaiting future RNA/DNA synthetic vaccines-their outcomes can vary a lot on account of the biological variability in raw materials and the steps involved in purification processes [8]; thus, patents on processes may help prolong their life cycles.

\section{Product}

Research and promotion have always been the major cost items for developing and marketing drugs, whereas manufacturing costs hardly ever account for a substantial proportion of total costs, with the last generation of sky-high priced 
mABs no exception [9]. In general, it is difficult to estimate single cost items per product in a research-oriented industrylike pharmaceuticals.

Conversely, manufacturing costs are the major ones for vaccines, which can have batch-to-batch variability and substantial changes in manufacturing processes requiring extensive analyses to show bioequivalence even after marketing approval [8]. Vaccines imply large-scale productions, which have traditionally discouraged the launch of off-patent and 'me too' vaccines [4]. High fixed manufacturing costs are diluted over many doses and are quite easy to post to each vaccine given their limited number. Recent trends have been to launch combination vaccines, including more than one antigen for reducing administration processes and new adjuvants for potentiating immune responses and/or sparing doses [10].

\section{Place}

General practitioners (GPs) are traditionally the major prescribers of drugs. Although the prescription of a growing number of new and expensive agents (e.g., mABs) may now be limited to the hospital settings in many European countries [11], most drugs are still prescribed by GPs and thus dispensed through community pharmacies.

Somewhat differently, the delivery of vaccines is more uneven throughout European countries, varying a lot according to the type of health care systems-e.g., Beveridge-type like in Italy and the UK, or Bismarck-type such as in France and Germany - and the national framework within the same type. For instance, in Italy, the vaccines recommended for children are administered in local health districts by public health professionals and those for adults by GPs in their cabinets [12], whereas in the UK all vaccines are mainly provided by general practices. Because most vaccines are still injectable, a common issue is that of storage and preparation [10]. Hence, beyond reducing injection overcrowding in health facilities, combo vaccines help contain storage and shipping costs [13].

\section{Promotion}

In a typical 'market failure' situation like pharmaceuticals, physicians (working as the patient's agent) fill the information gap of patients in medicine and take on their behalf the final decisions about how many and which drugs to prescribe among those available [14]. Hence, as prescribers, physicians are conventionally the major marketing target of pharmaceutical companies and aggressive strategies may raise financial conflicts of interest [15], eventually leading to drug overconsumption and bribery.

In contrast, vaccines do not normally require intensive promotion by industry. Campaigns to achieve high rates of coverage are mainly a task of health authorities, with manufacturers obviously interested in backing them up. Activities may consist of specific trainings for healthcare professionals and awareness campaigns for patients, except where vaccinations are mandatory, which is hardly ever the case in European countries nowadays [12]. Final results are substantially affected by public perception of vaccines values [1], with single physicians playing an important role in influencing vaccine hesitant families [16].

\section{Price}

Prices of new drugs have dramatically increased all over Europe in the last decade, making pharmaceutical expenditure somewhat unsustainable even in the (wealthier) Western countries. The most recent and ambitious price schemes (e.g., value-based pricing and outcome-based agreements) have shown intrinsic limits despite their scientific attractiveness [17], whereas sound strategies such as reference pricing and competitive tendering do not seem to be enough to stop the present trend of sky-rocketing prices. At present, the leading strategy for cost containment among European health authorities is to negotiate confidential prices directly with companies, an approach which inevitably lacks transparency [18].

Although many European health authorities have conventionally recurred to public procurement for buying vaccines, so as to exploit at most their purchasing power, the recent tendencies for pricing vaccines tend to follow those for drugs. Since any 'competitor' is (obviously) expected to be against price competition [19], nowadays the few (multinational) companies which market vaccines strive for undermining competitive tenders by differentiating their vaccines and launching the new ones (e.g., HPV and PCV) at prices which were unthinkable only a few years ago [20].

\section{Policy implications}

Vaccines are merit goods in public health aimed at safeguarding vulnerable people, no matter where they live [20]. Historically, vaccines have alleviated human suffering and prevented the loss of countless lives [21]. A very important lesson from COVID-19 is that there is no reason to assume Europe will be spared from pandemics requiring new vaccines in the future.

The number of recommended vaccines has substantially increased in the last decades [13]. The most recent vaccines include an increasing number of antigens in combination (e.g., DPT and MPR) and sero/genotypes (e.g., HPV and PCV). Of course, a single dose (oral) vaccine that immunizes children from all diseases would be ideally the most efficient solution [13], minimizing the workload of health 
authorities for administration. Also, an increasing number of high-risk subtypes included in a vaccine are expected to be an efficacy improvement, extending the protection against the targeted diseases.

From an economic viewpoint, vaccines are likely to be among the most efficient health interventions, potentially offering a cheap alternative to prevent long-term morbidity and mortality [22]. The opportunity cost-i.e., the cost of an alternative that must be forgone to pursue a new action - of a vaccine is expected to be low so that even the best drug treatments would be less desired [23]. Therefore, unsurprisingly, cost-effectiveness analyses based on the long-term models for justifying the request of high prices for new vaccines always conclude in their favour [19, 22].

Vaccines expenditure, like anything else, is the product of volumes and prices. Unlike drugs, volumes of vaccines are relatively easy to forecast, whilst, similarly to drugs, their prices may go quickly out of control, contributing to a further distortion in the allocation of financial resources in a 'market failure' context like health. Since there is no way to rank diseases according to their importance [18], and more generally to set a value for a human life [24], we can simply assume that all recommended vaccines are equally essential for the population's health, especially those for children whose social impact is essentially immeasurable [21].

Although it is the purview of public health experts to advise decision makers on which vaccines to recommend for reimbursement (hopefully) according to the existing epidemiological and clinical evidence [19], health economists cannot really contribute to setting the right prices of any health product, including vaccines. Instead of supporting irrational pricing, health economists could rather contribute to rational budgeting for managing vaccine expenditure in this apparently permanent period of economic crisis. Accordingly, here we put forward a practical proposal from the health authorities' perspective, particularly focused on pediatric vaccinations.

\section{From pricing to budgeting}

Once the national health authorities have decided the list of vaccines (and dose schedules) to recommend for their country, their payment procedures could be substantially revised to minimize the influence of (flawed) economic considerations on reimbursement decisions. The proposal open to debate can be broadly summarized in three points.

First, the yearly budget of vaccines could basically coincide with the national historical expenditure of the last year, to avoid any start-up shock, varying lightly in the future years on account of inflation/deflation, or growing more substantially according to eventual increases in the number of vaccinations recommended.
Second, national health authorities could reimburse to companies the same unit price for all the doses of vaccines administered on a monthly basis, calculated as the broad ratio between the total expenditure of vaccines and the total number of doses administered in the previous year. According to the existing estimates on the manufacturing cost per dose of vaccines [25] and to the prices offered to humanitarian organizations [20], an average unit price over $€ 15$ per dose in Western European countries should be profitable for any vaccine (e.g., the whole average price in Italy for vaccines recommended for children is around $€ 35$ ). If a company refused the unit price per reimbursement, claiming that it is too low to cover its costs without rebutting with solid information on the real manufacturing costs, health authorities could apply for compulsory licensing if the firm were the only one marketing the vaccine at issue, consistently to the European regulation.

Third, the unit prices of vaccines which do not achieve a high rate of coverage (e.g., 90\%) could be lightly decreased (e.g., $-5 \%$ ) from the second year until the target is achieved, in order to provide incentives for companies to support actively health authorities. A 'stick and carrot' financial incentive would address the (questionable) comment that the present price-based tenders of European countries could have negative (though unintended) effects on the rates of coverage [1], discouraging the provision of (unspecified) value-added services by companies.

To conclude, because we share the opinion that withholding from reimbursement any effective vaccine because of its high price is ethically disturbing [21, 24]; here, we raise a proposal to minimize the probability of such a negative event in an era of (really) finite resources.

Acknowledgement LG would like to thank his friend Marco Sozebro for his useful comments on the first draft of the manuscript.

Funding No sources of funding were used to conduct this study or prepare this manuscript.

\section{Compliance with ethical standards}

Conflict of interest Livio Garattini, Anna Padula and Nicholas Freemantle have no conflicts of interest directly relevant to this article.

\section{References}

1. Wilsdon, T., Lawlor, R., Li, L., Rafila, A., García, R.A.: The impact of vaccine procurement methods on public health in selected European countries. Expert. Rev. Vaccines. 19(2), 123 132 (2020)

2. McCarthy, JE.: Basic marketing. A managerial approach. Irwin, Homewood (1964)

3. Luyten, J., Beutels, P.: The social value of vaccination programs: beyond cost-effectiveness. Health. Aff. 35(2), 212-218 (2016) 
4. Danzon, PM., Pereira, NS.: Vaccine supply: effects of regulation and competition. [cited 2019 Sept 09]. Available from: https:// www.nber. org/papers/w17205 (2019)

5. Garattini, L., Padula, A.: Between pharmaceutical patents and European patients: is a compromise still possible? Expert. Opin. Ther. Pat. 27(10), 1073-1076 (2017)

6. Niazi, SK.: Biosimilar and interchangeable biologics: strategic elements. CRC Press Taylor and Francis Group LLC, Boca Raton, Florida (2016)

7. Dowling, D.J., Levy, O.: Pediatric vaccine adjuvants: Components of the modern vaccinologist's toolbox. Pediatr. Infect. Dis. J. 34, 1395-1398 (2015)

8. Plotkin, S., Robinson, J.M., Cunningham, G., et al.: The complexity and cost of vaccine manufacturing - an overview. Vaccine. 35(33), 4064-4071 (2017)

9. Garattini, L., Padula, A.: Precision medicine and monoclonal antibodies: breach of promise? Croat. Med. J. 60(3), 284-289 (2019)

10. Jacobson, S., Sewell, E.C., Karnani, T.: Engineering the economic value of two pediatric combination vaccines. Health. Care. Manage. Sci. 8(1), 29-40 (2005)

11. Garattini, L., Curto, A., Padula, A.: The puzzle of drug delivery in Italy: who wins? Expert. Rev. Pharmacoecon. Outcomes. Res. 16(3), 331-332 (2016)

12. Curto, A., Duranti, S., Van de Vooren, K., Garattini, L.: Vaccination planning and vaccine prices in a decentralizing country Italy. Expert. Rev. Pharmacoecon. Outcomes. Res. 14(2), 195-202 (2014)

13. Robbins, M.J., Jacobson, S.H.: Analytics for vaccine economics and pricing: insights and observations. Expert. Rev. Vaccines. 14(4), 605-616 (2015)

14. Garattini, L., Padula, A.: Competition in health markets: is something rotten? J. R. Soc. Med. 112(1), 6-10 (2019)

15. Garattini, L., Padula, A.: Conflict of interest disclosure: striking a balance? Eur. J. Health Econ. 20(5), 633-636 (2019)
16. Schaffer DeRoo, S., Pudalov, N.J., Fu, L.Y.: Planning for a COVID-19 Vaccination Program. JAMA (2020). https://doi. org/10.1001/jama.2020.8711

17. Garattini, L., Curto, A., Freemantle, N.: Pharmaceutical Price Schemes in Europe: Time for a 'Continental' One? Pharmacoeconomics. 34(5), 423-426 (2016)

18. Garattini, L., Padula, A.: Pharmaceutical pricing conundrum: time to get rid of it? Eur. J. Health. Econ. 19(8), 1035-1038 (2018)

19. Garattini, L., Padula, A.: Pricing of HPV vaccines in Europe: back to the Future? Appl. Health. Econ. Health. Policy. 16(3), 275-277 (2018)

20. Torreele, E., Mazzucato, M.: Fair vaccine pricing please, not random acts of charity. BMJ 355, i6173 (2016)

21. Mekalanos. JJ.: Vaccine economics: What price human life? Sci Transl Med. 5,204ed16 (2013)

22. van de Vooren, K., Duranti, S., Curto, A., Garattini, L.: Cost effectiveness of the new pneumococcal vaccines: a systematic review of European studies. Pharmacoeconomics. 32(1), 29-45 (2014)

23. van de Vooren, K., Curto, A., Garattini, L.: Curing cervical cancer or preventing it: A case of opportunity cost in the long run? Vaccine. 32(51), 6867-6869 (2014)

24. Meissner, H.C.: Immunization policy and the importance of sustainable vaccine pricing. JAMA 315(10), 981-982 (2016)

25. Clendinen, C., Zhang, Y., Warburton, R.N., Light, D.W.: Manufacturing costs of HPV vaccines for developing countries. Vaccine 34, 5984-5989 (2016)

Publisher's Note Springer Nature remains neutral with regard to jurisdictional claims in published maps and institutional affiliations. 